\title{
Michael E. DeBakey and Denton A. Cooley-Mike, the Master Assembler; Denton, the Courageous Fighter: A Personal Overview Unforgettable Past Remembrances in the 1960s
}

\author{
Domingo S. Liotta \\ School of Medicine, University of Morón, Morón, Argentina. \\ Email: medicina-trad@unimoron.edu.ar
}

Received July $12^{\text {th }}, 2012$; revised August $12^{\text {th }}, 2012$; accepted August $20^{\text {th }}, 2012$

\begin{abstract}
Domingo S. Liotta discovered Assisted Circulation at the Department of Surgery of Baylor College of Medicine in Houston in 1961 and opened up a new medical therapy: Prolonged mechanical Cardiocirculatory Assistance (LVASs) for the treatment of Refractory and Irreversible Heart Failure. The American Society of Cardiology selected Liotta's work for the "Young Investigator Award" granted in Denver in May 1962: "This prolonged left ventricular bypass decompresses the left ventricle, reduces left ventricular work, decreases left ventricular wall tension and increases coronary circulation" [1]. Indeed, there is a lucky occurrence in science; I had the good luck to start this research at a moment when initially unrelated developments were actively taking place in cardiac surgery, long before any rigor or fine statistics were produced. The first observation was to recognize an interaction between the overstretched myocardial fibers and the result of cardiac assistance causing their shortening within the normal values when the excess of blood volume retained in the heart chamber was unloaded, and the second one was that the oxygen consumption of the heart (a measurement of its energy use) decreases during Cardiac Assistance. With the collaboration of Michael E. DeBakey, Liotta started the clinical experience of Cardiocirculatory Assistance and on August 6, 1966 they succeeded in the first survival of a patient in postcardiotomy cardiogenic shock. Today, after 50 years, LVASs are in force in the medical practice worldwide and contrarily to transplantation practices, they have an unlimited future; they are continuously fed back by the scientific advances of general technologies. On April 4, 1969 Cooley and Liotta implanted the first clinical Total Artificial Heart (TAH) as a bridge to heart transplantation. So far, this has been the case of TAH use in which the patient could be extubated and weaned off the ventilator the following morning. This is a sort of historical document. The venerable visit of Mike DeBakey to Argentina in 1996 was evidence of his majestic peace harmonized in the memory and veracity of useful years.
\end{abstract}

Keywords: Michael E.; Debakey-Denton A.; Cooley-Total Artificial Heart-Assisted Circulation

\section{Introduction}

After over 50 years, the reflections of the events concerning our work on the creation of Cardiocirculatory assistance and the clinical use of the Total Artificial Heart at Baylor College of Medicine in Houston-events that touched the life shield-are well worth revisiting. Indeed, two giants in the 20th century, Michael E. DeBakey and Denton A. Cooley, each one with his own dreamy legend, developed cardiovascular surgery in Houston.

In the book, to some extent autobiographical, I published in March 2007 [2], I stated that the most important letter I ever received was in May 1961 while I was in the Cleveland Clinic. It was signed by Michael E. DeBakey.
He invited me to attend a fellowship program in his service of Cardiovascular Surgery in Houston for a year; in fact, my stay was extended to a decade, firstly as an American Heart Association's Advanced Research Fellow in Cardiovascular Surgery (62 F 92) and since 1964 as a professor of cardiovascular surgery at Baylor College of Medicine.

The invitation was rather related to our presentation in Atlantic City during the annual meeting of the American Society for Artificial Organs (ASAIO) in March 1961; today's line of work about drivers, electric motors, and mechanical and air-driven systems was presented along with the original prototypes and the animal results of 
experimental implantation [3,4]. Yet incredibly, engineer Taliani and I accomplished in only one year (1960) the first step of the three models of the artificial heart research in Córdoba, Argentina. When I had the good fortune to meet him initially in Córdoba, during the holiday season in 1959, he was a "young" seventy-six-year-old man. The unforgettable engineer Taliani died at eightyeight in Italy. I can clearly see in my memory our old and dear Taliani with a cap, bending over his working table while he joined piece by piece, with his old hands, the Dacron tissue cusps of the heart valves for the artificial heart. The perfection of the valves was the astonishing work of C. William Hall. Bill went to Córdoba in 1965 just to shake hands with Taliani.

As soon as I arrived in Houston, on 10 July 1961, I went to say hello to Dr. DeBakey in the Methodist Hospital and he asked me if, in addition to my training in cardiovascular surgery, I wanted to devote myself to work as part of my training — on the artificial heart in the Laboratories at Baylor University; I immediately nodded in agreement.

In Baylor University laboratories there was absolutely nothing to start a work of the magnitude of that we had undertaken in the National University of Córdoba with engineer Taliani. In fact, in July 1961 I only found a machine shop run by Mr. Louis Feldman, a diffident technician [5]. However, at that time I did not imagine the tremendous future enthusiasm of Lou Feldman, perhaps to some minor extent, but feeling the same intense attraction towards the research of the artificial heart that had seduced engineer Taliani in Córdoba. At that singular moment in Baylor, I myself had the valuable experience gained with the three models of artificial heart developed in our experimental work in the National University of Córdoba.

\section{The Discovery of Prolonged Mechanical Circulation for Caring Henceforward Those Patients in Advanced Heart Failure with Potentially Viable Myocardial Tissue}

While I was unhurriedly walking back to Baylor one evening in the fall of 1961-immediately after the death at the Methodist Hospital of a patient in postcardiotomy cardiogenic shock, it suddenly occurred to me that prolonged use (for several days or weeks) of mechanical circulatory support of the left ventricle with a small implantable pump (similar to the little pumps developed in Córdoba to be implanted in dogs) and without systemic heparinization might be the answer to support those dying patients; up to that moment we had been using extracorporeal circulation hourly support quite unsuccessfully.

During late 1961 and early 1962, I developed at Bay- lor a small intrathoracic air-driven pump-the latest system used by Taliani and me in Córdoba-that partially bypassed the left ventricle from the left atrium to the thoracic aorta. The pump housing was made of Silastic reinforced with Dacron fabric and inlet and outlet ball type valves were selected instead of the three-leaflet Dacron fabric used in Córdoba.

In May 1962, during the annual meeting in Denver the American College of Cardiology selected our work on Assisted Circulation as the best finalist of the Young Investigator Award. I vehemently presented the conception of prolonged Assisted Circulation at that unforgettable testimony in Denver [1].

On July 18, 1963, one of E. Stanley Crawford's patients, George Washington - which was, in fact, his real name- underwent an aortic valve replacement. The aortic valve was heavily calcified and was replaced with a Starr-Edwards mechanical valve. Early next morning, the patient had a cardiac arrest and was resuscitated by means of the open-chest technique. After the chest was closed, it was evident that severe brain damage had occurred. The patient remained in a coma, with low cardiac output and anuria. Without a proper pumping action the production of urine was nil. Subsequently, a rather severe pulmonary edema developed and he was refractory to standard treatment.

Crawford and I implanted the first clinical LVAD (Left Ventricular Assist Device) in the history of medicine in this patient in the evening of July 19, 1963, by bypassing the left ventricle from the left atrium to the descending thoracic aorta through a left thoracotomy incision. The pump was regulated to bypass with 1800 to $2500 \mathrm{~mL}$ of blood per minute. Despite the anuria that had been present since cardiac arrest persisted, the pulmonary edema cleared, as indicated by plain chest X-ray and auscultation of the lungs. We discontinued mechanical support after four days of continuous use, but the patient remained in a coma and died.

On April 21, 1966, the Liotta-DeBakey Paracorporeal Left Ventricular Assist Device (LVAD) was implanted for the first time in medicine in Mr. DeRudder, a patient in cardiogenic shock postcardiotomy. The Liotta-DeBakey was the first clinical paracorporeal pump (Figure 1).

On August 6, 1966, a patient from Mexico, Ms. Esperanza del Valle V., underwent a double valve replacement but could not be weaned from extracorporeal circulation. Then, we implanted a paracorporeal left ventricular assist device from the left atrium to the right axillary artery. After support by the ventricular assist device for ten days at a flow rate of $1200 \mathrm{~mL} / \mathrm{min}$, the patient recovered, which made this the first successful use of a Left ventricular assist device for postcardiotomy shock. 


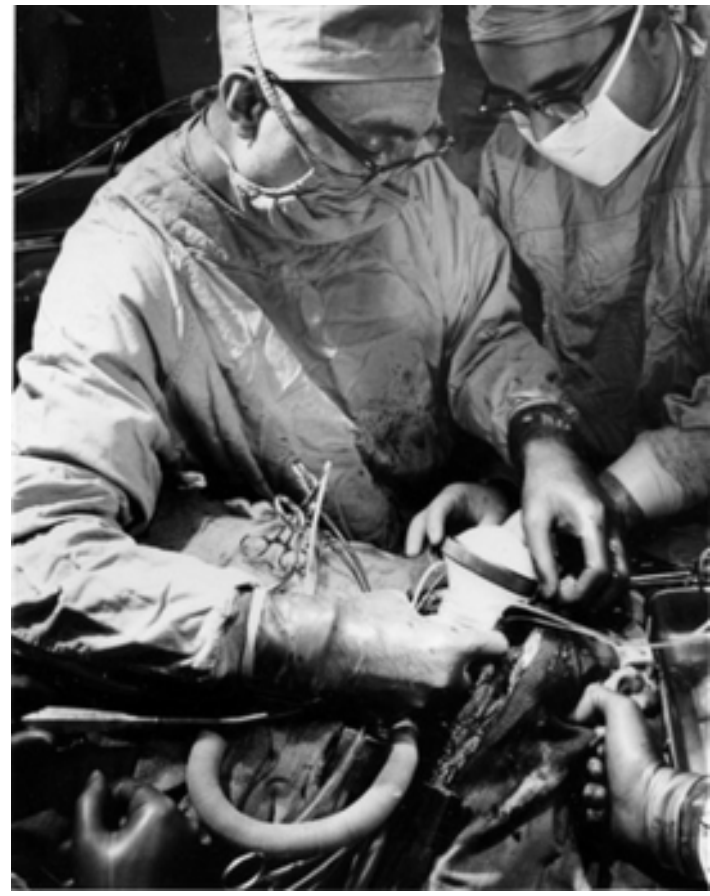

Figure 1. Paracorporeal LVAS. Dr. DeBakey, on the left and Dr. Liotta (April 21, 1966) (This picture also appears at: www.arlingtoncemetery.net/medebakey.htm).

In my autobiographical book, I acknowledged Michael E. DeBakey, who played an important role in the surgical design of the paracorporeal pump implantation in this patient [2, p. 177]. For example, the choice of longer percutaneous connectors to bypass the left ventricle from the left atrium to the right axillary artery was his suggestion.

In DeRudder's surgery we had used short intrathoracic connectors, with the body of the pump placed at the skin's level. In this patient, the outlet connector was sutured to the right axillary artery to avoid an ascending aorta implantation. It helped the removal of the pump without reentering the chest, and the left atrial connector was left in the chest cavity undisturbed.

Sadly, about ten years later, Ms. Esperanza del Valle died in Mexico in a car accident.

Around 1998, at the School of Medicine of the University of Morón, we started the design, the making, and the animal implantation of a new system, the novel LVAS [6]. Novel LVAS may be a bridge to cardiac transplantation. However, the main indications are both Functional Heart Recovery and Destination Therapy. Several basic considerations were taken into account in the design of this new system: 1) We did not want to cannulate heart chambers; 2) In particular, we rejected the use of left ventricular apical cannula - for the pump's inflow-for myocardial recovery patients or destination therapy, because it contributes to destroy the already se- verely damaged myocardium helical anatomy of the left ventricle; 3) We chose the atriostomy method (pump inflow). A large opening in the left atrial wall for blood inflow to the implantable pump is made; a $25-$ or $30 \mathrm{~mm}$ diameter atrial prosthesis is sutured to the epicardial side of the left atrial wall (at the atriostomy opening). The atrial prosthesis is fitted with a titanium frame, which keeps the atriostomy permanently open; 4) In the latest model, we have employed a small continuous flow pump with the atriostomy method for pump's inflow and the higher segment of the left axillary artery for the pump's outflow. The continuous flow pump remains either in an intrathoracic or extrathoracic position and is fixed at the level of the thoracotomy, at the 5th intercostal space.

\section{Mike Debakey, a Unique Personality}

What went through Mike's mind from May 1962, moment of our presentation in Denver, to 19 July 1963, when he put pressure on Stanley Crawford for the implantation of Assisted Circulation to a patient in a deep coma?

The analysis of this temporary halt in the personality of Mike DeBakey has a special significance. Firstly, it is clear that before requesting a definitive and great program for Baylor University, with unrestricted funds from the federal Government, Mike wanted a minimal clinical trial. And that basic test was the result of the chest X-ray films of Stanley Crawford's patient. Before the circulatory assistance, the films showed an advanced lung edema and during the assistance the chest $\mathrm{X}$-ray films showed a total disappearance of the pulmonary edema. The presentation of these chest X-ray films was the key to his celebrated strategy in Washington; no strategy has surpassed Mike's strategy so far [7].

\section{Michael E. DeBakey’s Rice-Baylor Artificial Heart Program}

The Program was confirmed early in 1964. From the very beginning, we defined the working lines and responsibilities in Rice University, establishing two groups, i.e. chemical and electronic engineers. William Akers, a chemical engineer, and his specialist partners would be responsible for the search of new biomaterials. In the other group, John H. Maness was the head of the electronic engineers, directly responsible for driver development. Mike DeBakey was the director of the full RiceBaylor program, being Domingo Liotta the co-director.

Shortly afterwards, Maness quit Rice University and established his own research laboratory, but remained at our entire disposal for any consultation.

In fact, after July 1968 Maness - with the assistance of William O’Bannon—was the engineer who, under my 
instructions on physiological hemodynamic guidelines, directed the construction of the advanced clinical driver for the Total Artificial Heart used on April 4, 1969. Engineer O'Bannon, an employee of Rice University, was directly responsible for the driver's management and functioning [2, p. 105]. Unfortunately, he had a nervous breakdown in the afternoon of April 3, and engineer John Jurgens successfully did a master work, thus resolving the singular moment.

After almost half a century, it would be worth assessing the usefulness of the Baylor-Rice artificial heart program created - with his unsurprising intellect-by Dr. DeBakey. Accordingly, it is my personal belief that, in the first place, it was a good and honorable thing, a true accomplishment related to our research work, coming from Mike DeBakey. On a speculative side, it intrinsically clearly penetrates into Mike's real passion for the artificial heart research. We just have to observe his anxiety in the midst of his main struggle with Denton Cooley, following the clinical Total Artificial Heart in 1969, when his life was disturbed to a greater extent than necessary; subsequently, a strictly medical affair had inevitably the harshness of public affairs. Finally, the dangerous quarrelling between great personalities abated the outstanding Rice-Baylor project for ever.

Hence, after years of reflection, it is difficult to estimate the true significance of the sudden and profound destruction of the artificial heart Rice-Baylor project.

It is problematic to estimate, at least for me, the true significance of those things. Highly educated professsional men, in independent position, and with honest purposes, remained, for years, in a hopeless confrontation. The facts were finally frightful enough; unfortunately, they marked the standby of everything for which Mike had labored in arduous but serene action in the field of prolonged artificial circulatory research.

\section{Research on the Formation of an Autologous Interface between the Ventricular Prostheses and the Patient's Blood. The First Step toward the Clinical Use of Blood Pump Devices}

We started this crucial research in 1964 and continued it in 1965: The formation of an autologous interface made up by fibrin and blood corpuscles from the patient that are incorporated in a permanent way into the lining of the prosthesis in contact with blood (development of a blood-foreign material interface-an autologous cellular interface) $[8,9]$. The fibrin and the blood corpuscles, the cardiac prostheses were lined with a special Dacron "velour" that I personally developed in Philadelphia with the people recommended by Mike at the Philadelphia College of Textile. All of our prostheses in clinical use since 1966 had this lining and the thromboembolic incidence was null. Some of the recent LVASs, even on metallic surfaces, have adopted this principle, the creation of an autologous interface with the patient's blood.

\section{Replacement of Total Artificial Heart Function}

In 1964 we published a "celebrated" paper of which I am heartily glad [10]. It was a breakthrough study. At that time we were already thinking on the complete replacement of the heart function at Baylor.

However, in 1964 we were vaguely interpreting objectives to go into real action in moribund patients. Unquestionably, veracity to facts, we were not yet prepared, even from the psychological point of view, for this great step in 1964.

It is well known that members of the Department of Surgery of Baylor College of Medicine-DA Cooley, surgeon; DS Liotta, surgeon; GL Hallman, surgeon; RD Bloodwell, surgeon; A. Keats, anesthesiologist; RD Leachman, cardiologist - finally did at the Texas Heart Institute, on April 4, 1969, the two-staged total heart replacement procedure in a moribund patient, in order to "buy time" while waiting for a donor $[11,12]$. The historical clinical implantation of the first Total Artificial Heart in 1969, has undeniably been legitimate, and may be added up to the United States lasting glory. In 2006 the Smithsonian Treasures of American History Exhibit, selected the 1969 original prototype to be displayed prominently [2, p. 289]. Truly, it was the honest appeal of the unquestionable, unrestricted medical duty, assuredly seeking at that time advancement of institutions that had to thoroughly join their efforts regarding artificial heart research. I am referring to both the Texas Heart Institute and the Department of Surgery of Baylor College of Medicine under the chairmanship of Professor Michael E. DeBakey.

And, here I will express my unchangeable testimonythe testimony of research unity-concerning the occasion on which I had a face-to-face secret meeting with Dr. DeBakey early in the morning of April 20, 1969, just before flying to Atlantic City for our ASAIO presentation together with Dr. Cooley. Indeed, that morning, solemnly though very strongly, Dr. DeBakey told me I should consider desisting from the idea of being in Atlantic City for attending the ASAIO meeting. At the end of that hard day, I had at least a majestic peace; the noble Willem J. Kolff asked the ASAIO audience for a standing ovation for Dr. Liotta, "for the skill and persistence with which he has pursued the artificial heart" [12, p. 266].

It is well-known, even by the general public, that after April 4, 1969 a profound disagreement started among Mike DeBakey, Denton Cooley and other medical per- 
sonalities, concerning the design and the place where the blood pumps had been built; a fact that enabled the first implantation of a total artificial heart in the history of medicine.

This controversy was largely explained in a book published in 2007 [2, p. 236], from which I will extract a few essential sentences.

In July 1968, a patient of Denton Cooley developed a stone heart in OR1 following a difficult replacement of severely calcified aortic valve. Robert Bloodwell removed the heart from a sheep in OR2 and Denton, in a frantic effort to keep his patient alive, replaced the heart with the sheep's heart. With justice, indeed, the ennobling reaction of Denton was not looking for a permanent xenotransplant but was just fighting - in July 1968- “to buy time” until a proper human donor heart was available. Instantly, when the patient's blood started flowing into the coronary arteries of the sheep's heart, a hyperacute rejection followed.

Thoughtfully, Cooley, Bloodwell and I went down to the cafeteria of St. Luke Hospital at about 6 p.m. At that very moment, we realized that in order to keep the patient alive until a human donor heart could be found, the unique solution would be to implant a Total Artificial Heart. I fully agreed, and indeed, it is not needful to express my full conviction of this wisdom.

In July 1968, I started the design and making of the Clinical Total Artificial Heart at the laboratories of Baylor College of Medicine. I immediately called both John Maness, to help in the design of the clinical compact driver, and my old friend Paul Kahn from Cutter Laboratories (Berkeley Ca.), for the Wada-Cutter valve prostheses.

When Denton and I met at the "celebrated Christmas Concord" in December 1968, the technical aspects of the full procedure were practically resolved. Early in January 1969 Denton and I started the experiments of total artificial heart implantation in calves at the laboratories of Baylor College of Medicine. In our bovine experimental work we employed two current blood pumps made at Baylor laboratories, and two separate old drivers, used at Baylor for LVAD experiments, to energize both ventricles respectively.

Indeed, after over four decades, the only question worth discussion is whether Mike DeBakey was wholly aware of the project of the younger members of his own Department of Surgery. Firstly, I am positively sure that Mike was acquainted with the extension and advancement of our work at Baylor. Really, at Baylor everybody was familiar with it, including Mike's Residents-some very close to him - they were continuously asking us about the progress of our work; and, purposely, we gave the utmost information to them, maybe with an amplifi- cation or hyperbole.

Secondly, I gave frequent information of our activity to Mr. Jerry Maley, administrator of the Department of Surgery, a close confident of Mike at that time. I necessarily would sign the initial papers to request animals and materials for our experimental work. Indeed, the only question worth discussion is that we needed sundry reasons to answer the fundamental question; there seemed that we were actually avoiding a face-to-face direct confrontation with Mike. The ingenious strategy was to patiently wait for a call from Mike rather than to confront him with our already advanced work. At any rate, for almost nine months we were looking for a restricted opportunity to exchange information with Dr. DeBakey on our artificial heart clinical project; nevertheless, the suddenness of our confrontation with a moribund patient was rather striking.

So, I venture to offer a reason of my own that touches the higher problem of mutual confidence. I am convinced that Denton and I were instinctively anxious about Mike's reaction, in the logic that he might show a disposition to definitively stop our work, and our moral and practical tenacity to the artificial heart project were already unalterable; we could not stop it, and then the most plausible reason, after long reflection today, is that we were excessively plunged into a truly forewarning instinct. Now, it is perfectly true that never had Mike said a word on this subject before April 4.

Then, I deplore that we could not discern Mike's real temper and his understanding on our clinical artificial heart project before April 4, 1969. The true question following Mike's reaction on April 4, 1969 is evidently obvious. However, something is absolutely right, regarding our respectful attitude; in the afternoon of April 4, Denton—still working in the OR1—asked Bob Leachman to call Dr. DeBakey to inform him of what was going on at the Texas Heart Institute in the afternoon of April 4. Unfortunately, Mike was already flying to Washington; and the worst thing was the fact that the following morning Dr. DeBakey entered the room at the $\mathrm{NIH}$ meeting in Washington and received the warm congratulations on the artificial heart implantation by the NIH members.

Again, on the speculative side I may, in short, say that we made the clinical blood pumps in Baylor laboratory; the four Wada-Cutter valve prostheses and the Clinical Driver had been donated by the Cooley Foundation. The Bjork-Shiley valve prostheses were not available at that time for us.

Bill Hall was strictly right when admitting during the tough controversies after the Total Artificial Heart implantation that Dr. Liotta had been working in blood pumps models for a long time—at least since 1964. 
Bill was, undoubtedly, fairly right, if we observe the Figure 2 taken around 1965 in my office at Baylor. In the foreground, the prototype of the small pneumatic driven blood pump used in our experiments in the National University of Córdoba in 1960 can be seen. All the pumps made at Baylor-shown in this picture, on the table and in my hands-descended from this early Liotta-Taliani prototype even those pumps implanted in a patient on April 4, 1969 [2, pp. 186-190]. In the ASAIO presentation in 1969 a photograph and a drawing were shown to perfectly correlate the Liotta-Taliani model with the design of the implanted patient's pump [12, p. 256].

Doubtlessly, there was a variation in the transition of making clinical models adapted to the human chest rather than laboratory blood pumps for bovine experimentation, and the tremendous responsibility for making clinical pumps rather than experimental units. The adaptation to human chest was a careful task; the vulnerable compression of the left inferior pulmonary vein when the median sternotomy was closed was Denton's constant concern, and the absolute reliability of compact clinical drivers with the obligatory redundancy of all the electric circuit boards, a responsibility shared with J. Maness.

On some occasions, I was faced up to the fact of rather short time from July 1968-date of the decision to head for the clinical artificial heart-and April 4, 1969. Now, we can understand that during that short period of time Dr. Cooley and I did an arduous work to adapt the experimental bovine pumps to a clinical model. Certainly, sharing the clinical understanding with Denton was for me a rewarding experience in this crucial step [11,12],

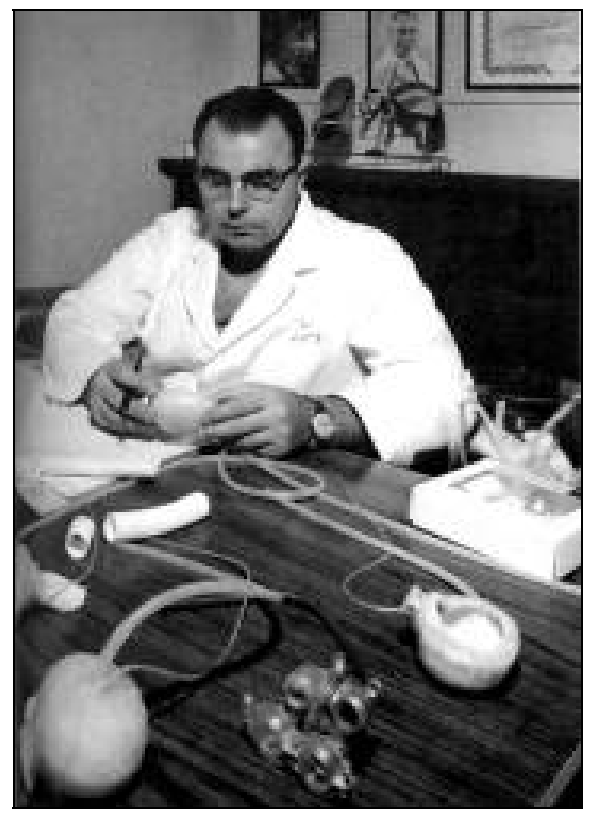

Figure 2. Domingo Liotta at his office in Baylor College of Medicine around 1965, see text for further explanation.
(Figures 3 and 4).

The first operation in medical history. Total heart replacement with an Artificial Heart (orthotopic position). On the left, Dr. Liotta; in the center of the picture, the empty pericardial sac of the patient, Mr. H. Karp. On the right, the hands of Dr. Cooley holding Mr. Haskell Karp's heart and the Liotta-Cooley Artificial Heart just before implantation. Texas Heart Institute, Houston (April 4, 1969). Lower right corner of the picture: Dr. Cooley is holding both the removed artificial heart and the donor heart (April 7, 1969).

\section{Mike DeBakey in Argentina, May 1996}

I sent Mike an official invitation from the Argentine Government in my capacity as the State Secretary for Science and Technology.

My sons, Domingo Jr. and Carlos Augusto, did an in-

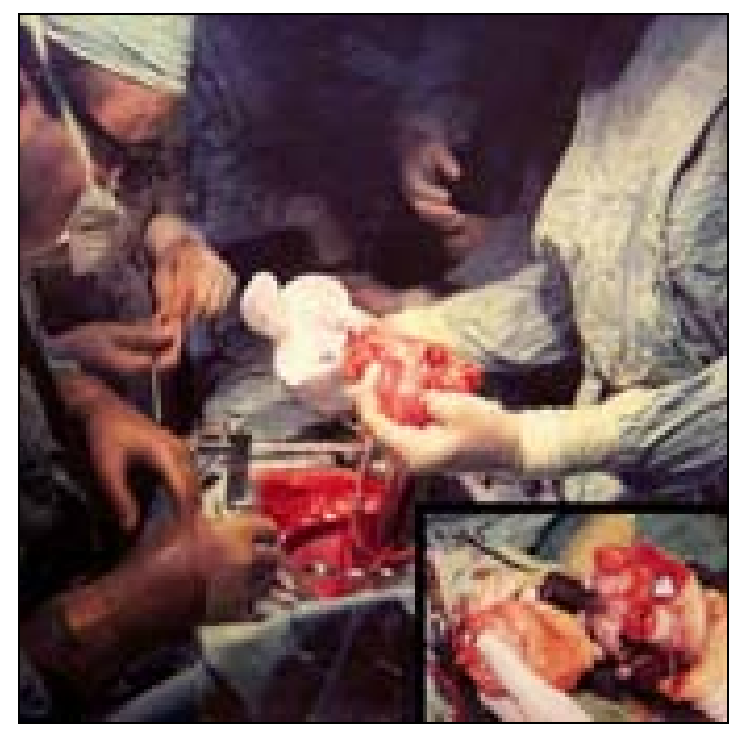

Figure 3. The symbol of clinical total artificial heart.

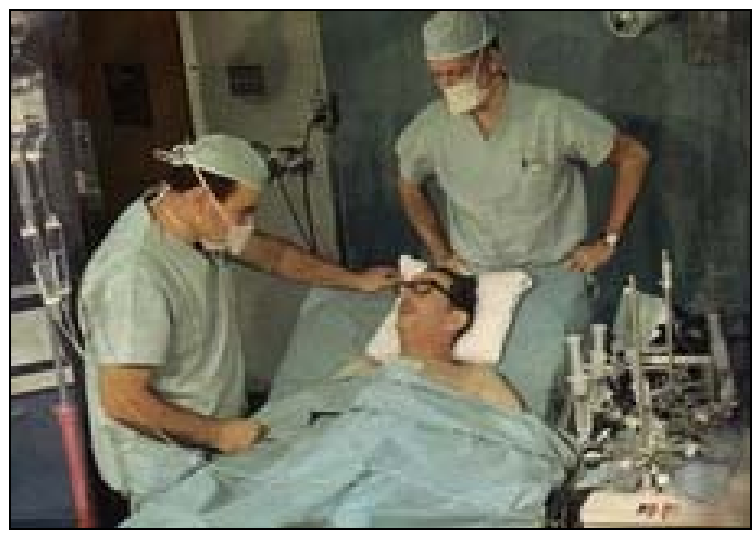

Figure 4. The symbol of human conscience and total artificial heart: Dr. Liotta is talking with Mr. Karp and Dr. Cooley observing, April 5, 1969. 
ternship at the computing and information technology facilities in the Methodist Hospital in Houston during the month of February 1996 and they took the invitation to Mike, who immediately and gladly accepted it.

Now, I am fully aware of the responsibility I have of telling about Mike's visit to Argentina, in 1996, especially considering 1969 controversies, a visit that lasted about one week.

In 1996 Mike DeBakey was 88 years old. He had not changed his physical aspect from the time I had met him in Houston, and he was so dynamic as in his best time. However, Mike was another person from the spiritual point of view. I mean, different in the serenity he radiated, relaxed at all times, and in his singular capacity for meditative actions with a remarkable insight.

The serenity that I observed in Mike in 1996 is the serenity of the authentic fighters when they retire from the arena that has been their battleground.

In the eyes of his residents and fellows Mike was a harsh and choleric man [2, p. 234]. I rather believe that the precedent expressions were from youngsters intensively looking for an identity as cardiovascular surgeons. Mike's advocacy of a well done work is well known; he encouraged intellect superiority.

Truly, Mike was a master that served his authority intensively, and in this regard he reminds me of my dear "Maestro" in General Surgery in the National University of Córdoba, Professor Pablo L. Mirizzi.

I myself performed cardiac surgery until I was 82; Mike was active in the operating room until 80 , as well as Denton Cooley, and when they retired the serenity of the authentic old workers described by Jacques Maritain, the celebrated French Christian writer and philosopher, arose. Maritain described marvelously Saint Paul's serenity in his last days; in $67 \mathrm{AD}$ he was executed in Rome, being Nero the Roman Emperor until the year 68 AD.

At the end of his days, the Apostle remained in a state of great serenity to look back the path in his life and express the fruits of the struggle, the experience and the pain. Maritain extends his understanding to the old retired workers: "C'est une des plus belles choses humaines que la sérénité de vieux ouvriers" (The serenity of old workers is one of the most beautiful things in humans). The old Paul had known all dropouts, his confidence was serene. Paul knew he had worked hard and had worked for God [13, p. 72].

The President's welcome and kindness, in the academic act held in the White Chamber of the Government House on May 15, 1996, with the presence of distinguished personalities, was a true apotheosis for Mike (Figure 5).

Indeed, this was a singular moment during the official act, after DeBakey's words for thanking and evoking his memories. The President's gift was a historic photograph of his first clinical operation of circulatory assistance, the implantation of Liotta-DeBakey paracorporeal pump in the patient called De Rudder on 21 April 1966 (Figure 1).

To see the photograph and before extending his arm to take the President's gift, Mike lowered his head and gave me a look full of sadness. Thus, Mike observed the seriousness of my expression in respectful testimony and serene thanks to his person; then I myself took the picture with both hands and stood next to Mike to observe it and to remember our fighting old times; then Mike smiled. I have a picture of that singular instant.

Mike's grief lasted only a few seconds, but his look at the presidential podium with such a painful sadness has been etched in my mind ever since; I have never been able to forget the sad eyes of Mike plunged into a deep and austere melancholy. Occasionally, I even have a strange thought that reminds me of the time of De Rudder's operation as a heartless act on my part, joining the chorus of his detractors; but this is not a certain assumption because Mike was fully aware of the nobility of my indebtedness to him as well as my true admiration.

Firstly, regarding De Rudder's surgery Mike received unfair criticism concerning the patient's management from cardiac surgeons. Indeed, great men like Mike cacy was forged under the rigid and strict Bacon's doctrine about scientific rules: Obey first to be able to com DeBakey do not perform stage tricks with futile doctrines; Mike always advocated what he said and did; his advo mand afterwards. Rightly, we must be able to follow-to obey-the laws of science first to be able to command later in the realm of nature.

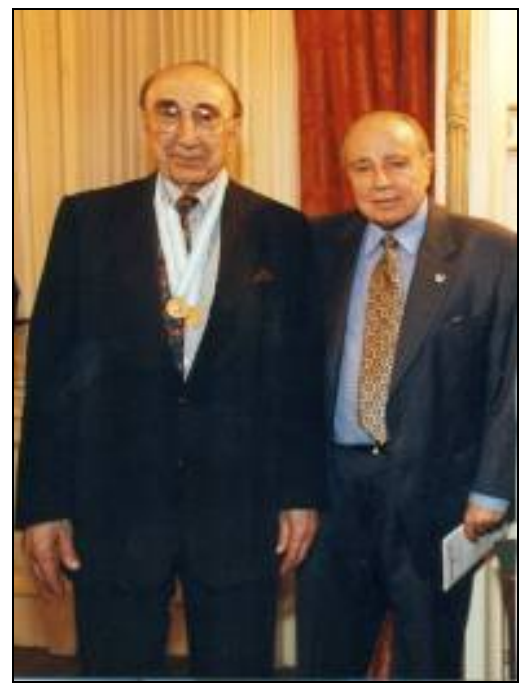

Figure 5. On the left, Dr. DeBakey at the Government House just after having been decorated by the President of the Argentine Republic, Dr. Carlos Saúl Menem; on the right, Dr. Liotta Buenos Aires, May 15, 1996. 
Those days of Mike, fighting for the life of De Rudder, have been unforgettable to me; I close my eyes and I can see Mike anxiously moving around De Rudder's bed, changing maybe the respirator units to get a better tissue oxygenation; since those days Mike has been my hero for evermore.

One day after lunch, I took Mike to CONICET laboratories located at Vuelta de Obligado and Monroe in Buenos Aires. Mike was exultant in the presence of other researchers; he watched carefully the units of cardiac care in construction, and had pleasant moments with the engineers of my PROCOAR (Pro-Artificial Heart) official program of the CONICET. In remembrance of his memorable visit, at the entrance of the laboratory was later placed a golden plaque that reads:

"Michael E. DeBakey went through this door to visit Domingo S. Liotta's CONICET laboratory."

"Dr. DeBakey, a world great figure in cardiovascular surgery and outstanding personality of the 20th Century medical progress, May 1996.”

In all that unforgettable week of May 1996 I never talked to Mike about the implantation of the first artificial heart in 1969. Besides, in a meeting with journalists coordinated by Luis de la Fuente, an Argentinean cardiologist, as an answer to the specific question, Michael DeBakey raised his head, directed his eyes to me and said: "Indeed, the concept of Circulatory Assistance was created at Baylor College of Medicine". And that was a crucial instance: Mike's recognition to researchers and his homage towards the creative intellect.

There is sometimes a practice, not uncommon in the United States, that the person that has attained the economic resources to conduct the research is the "owner" of the soul and the intellect of creators that are really working on the objective.

And this unique decision on the point of the economic aspect only, with no recognition of the creator's intellect is unsafe. Really, the increasing perfection of research cannot be accompanied by an increasing debasement of those who carried it on. The freedom to "seek new ways" is the most desirable action in order to have excellent research schema. A good authority must recognize what has been accepted from unrecorded times, that is the large freedom of young researchers. The freedom of the intellect is the most amazing phenomenon of humanity; it is sacred. Anyway, the economic aspects to support research and the institution where the discovery took place are undeniably significant from the historical point of view too.

\section{The Last Moments of Mike DeBakey in Argentina, May 1966}

Mike's farewell was carefully planned at the State Secretariat for Science and Technology in the afternoon.
Mike was very communicative. I mentioned to Mike that the following day I was travelling for an official visit to Syria and Lebanon to know their universities and deliver a couple of conferences on our cardiac surgery at the Italian Hospital of Buenos Aires. Mike suddenly said, "Domingo, I am very proud of coming from a Lebanese immigrant", and added "I will call a friend of mine in Beirut, just in case you may need a hand". Indeed, Mike's friend, an old surgeon in Beirut, called me when I was there.

By that time I was determined to organize the School of Medicine of the University of Morón after the end of my tenure as the Secretary of State for Science and Technology. On May 14, 1996 I was awarded the distinction of Doctor Honoris Causa by the University of Morón and received a concrete proposal from its Rector, at that time Dr. Omar Lima Quintana, an attorney, to start the School of Medicine. In an informal conversation I told Mike about the project and I was absolutely surprised when he pronounced the following words: "Domingo, I want my daughter Olga to come to Argentina to study medicine with you", and again insisted on that idea when my son Carlos took him to the airport, "remind your father of my greatest desire as regards my daughter Olga's studies." Nevertheless, one thing is what a father may wish, and another one is the decision a modern teenager may independently make.

In a few minutes two of my sons, Domingo Jr. and Carlos Augusto, would take Mike to the airport and he would leave for the United States. I went out of the Secretariat of State building to say goodbye to Michael DeBakey.

And at that very moment I had the greatest surprise of my life. With immense emotion "the former terrible black Mike" shook my hands, hugged me, held me in his arms and kissed me on my cheek; my two sons-really amazed-witnessed the incredible moment. Finally, I could understand: "This is the real eternal DeBakey" [2, p. 237].

"Lao Ren, Lao Ren" is a Chinese expression that I have heard so many times in China. It literally means "old man, old man", but its real sense is "wise man, wise man”. Lao, Ren, Lao Ren Professor Michael E. DeBakey, memorable beloved master.

Dr. DeBakey died in 2008, two months before reaching 100 years old. And, what seemed impossible a few months before his death happened: Mike made peace forever with Denton; a life example which has shaken the medical world.

\section{REFERENCES}

[1] D. Liotta, D. A. Cooley, M. E. DeBakey, et al., "Prolonged Assisted Circulation during and after Cardiac or 
Aortic Surgery: Prolonged Partial Left Ventricular Bypass by Means of Intracorporeal Circulation," The American Journal of Cardiology, Vol. 12, No. 3, 1963, pp. 399-405. doi:10.1016/0002-9149(63)90235-2

[2] D. Liotta, "Amazing Adventures of a Heart Surgeon. The Artificial Heart: The Frontiers of Human Life," iUniverse Inc., New York, 2007.

[3] D. Liotta, T. Taliani, et al., "Artificial Heart in the Chest: Preliminary Report,” Transactions-American Society for Artificial Internal Organs, Vol. 7, No. 3, 1961, pp. 318322.

[4] D. Liotta, T. Taliani, et al., “Ablation Expérimentale et Remplacement du Coeur Par un Cœur Artificiel IntraThoracique,” Lyon Chirurgical, Vol. 57, No. 4, 1961, pp. 704-714.

[5] D. Liotta, "Early Clinical Application of Assisted Circulation," Texas Heart Institute Journal, Vol. 29, No. 3, 2002, pp. 229-230.

[6] D. Liotta, "Novel Left Ventricular Assist System ${ }^{\circledR}$ (Novel LVAS): An Electrocardiogram-Synchronized LVAS That Avoids Cardiac Cannulation,” Texas Heart Institute Journal, Vol. 30, No. 3, 2003, pp. 194-201.

[7] M. E. DeBakey, D. Liotta and C. W. Hall, "Left Heart Bypass Using an Implantable Pump. Mechanical Devices to Assist the Falling Heart," Proceedings of a Conference sponsored by the Committee of Trauma, 1964, National Academy of Science, National Research Council, Washington DC, 1966, pp. 223-239.
[8] D. Liotta, C. W. Hall, A. Villanueva, R. M. O’Neal and M. E. DeBakey, “A Pseudo Endocardium for Implantable Blood Pumps,” Transactions-American Society for Artificial Internal Organs, Vol. 12, No. 8, 1966, pp. 129-138.

[9] J. J. Ghidoni, D. Liotta, J. G. Adams, R. M. O’Neal and C. W. Hall, "Implantation of Autologous Tissue Fragments in Velour Fabric Used to Line Cardiovascular Prosthesis: An in Vitro Culture System to Produce Cellular BloodProsthesis Interfaces,” Journal of Biomedical Materials Research, Vol. 2, No. 2, 1968, pp. 201-208. doi:10.1002/jbm.820020203

[10] D. Liotta, C. W. Hall, D. A. Cooley and M. E. DeBakey, "Prolonged Ventricular Bypass with Intrathoracic Pumps," Transactions-American Society for Artificial Internal Organs, Vol. 10, No. 10, 1964, pp. 154-156.

[11] D. A. Cooley, D. Liotta, G. L. Hallman, R. D. Bloodwell, R. D. Leachman and J. D. Milam, "Orthotopic Cardiac Prosthesis for Two-Staged Cardiac Replacement," American Journal of Cardiology, Vol. 24, No. 5, 1969, pp. 723-730.

[12] D. A. Cooley, D. Liotta, G. L. Hallman, R. D. Bloodwell, R. D. Leachman and J. D. Milam, "First Human Implantation of Cardiac Prosthesis for Total Replacement of the Heart," Transactions-American Society for Artificial Internal Organs, Vol. 15, 1969, pp. 252-266.

[13] J. Maritain, “La Pensée de Saint Paul,” Longmans, Green \& Co. Inc., New York, 1941. 